ARTIGO

\title{
A importância da Educação Superior na redução das disparidades de renda em Santa Catarina
}

\author{
Amanda Maciel da Silva a \\ Mário César Barreto Moraes ${ }^{b}$ \\ Sulivan Desirée Fischer ${ }^{c}$ \\ Cláudia Maffini Griboski d
}

\section{Resumo}

O estado de Santa Catarina situa-se na terceira posição no ranking dos estados brasileiros, considerando o IDH-M, em documento apontado pelo Pnud. Embora esse dado seja favorável, a Educação catarinense encontra lacunas que permitem questionar o desenvolvimento sustentado. Esta pesquisa, de abordagem quantitativa, analisa a importância da Educação Superior no desenvolvimento econômico do estado. A partir do Gini de renda e do Gini educacional, calculados a partir dos dados da Rais de Santa Catarina, entre 2006 e 2017, os índices de concentração de desigualdade permitem inferir que o estado apresenta desigualdades não reveladas por essas médias. A pesquisa permite concluir que a desigualdade vem aumentando ao longo dos anos e que as diferenças nos ganhos salariais entre Ensino Médio e Superior ultrapassam 150\%. Percebe-se uma tendência de concentração dos trabalhadores com Ensino Médio em detrimento das demais faixas de escolaridade.

Palavras-chave: Educação Superior. Desigualdade. Renda. Escolaridade. Índice de Gini.

\footnotetext{
a Universidade do Estado de Santa Catarina, Florianópolis, SC, Brasil.

b Universidade do Estado de Santa Catarina, Florianópolis, SC, Brasil.

c Universidade do Estado de Santa Catarina, Florianópolis, SC, Brasil.

d Universidade de Brasília, Brasília, DF, Brasil.
} 


\section{Introdução}

O Programa das Nações Unidas para o Desenvolvimento (Pnud) ${ }^{1}$, a propósito do índice de desenvolvimento humano (IDH), apontava Santa Catarina, em 2010, como terceiro lugar no ranking dos estados brasileiros com melhor IDH. Em termos de riqueza, traduzida pelo produto interno bruto (PIB), Santa Catarina ocupava, em 2016, o sétimo lugar no ranking dos estados brasileiros. Em termos de densidade demográfica, o estado ocupa a oitava posição, segundo estimativa feita pelo Instituto Brasileiro de Geografia e Estatística (IBGE), para a população de 2018. De acordo com essa estimativa, Santa Catarina possuía uma população de 7.075.494 habitantes em uma área de $95.346,181 \mathrm{Km}^{2}$, resultando em densidade demográfica de 71,52 habitantes $/ \mathrm{km}^{2}$ caracterizando-o como um estado populoso.

Na Figura 1, retratam-se o Índice de Desenvolvimento Humano Municipal dos estados brasileiros, à esquerda, e o IDH-M Renda, à direita, para o ano de 2010, última estimativa feita pelo Pnud. Levando-se em consideração essas categorias, todos os estados situam-se nos intervalos de médio e de alto desenvolvimento humano.

Figura 1 - IDH-M e IDH-M Renda do Brasil por UF
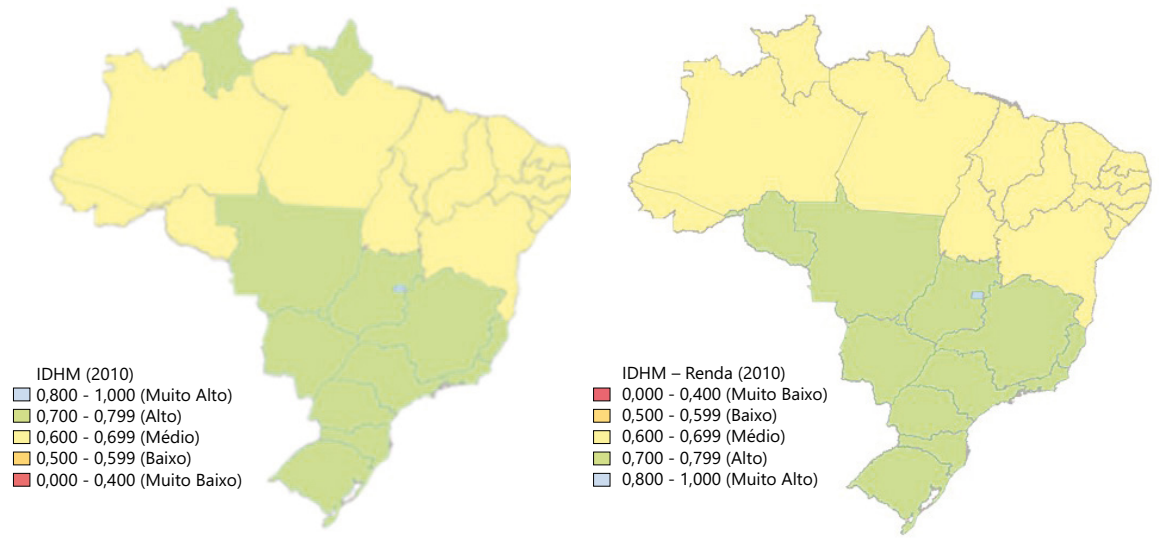

Fonte: Elaboração própria a partir do software QGis e dados do Pnud (ATLAS DO DESENVOLVIMENTO HUMANO NO BRASIL, 2018).

1 Disponível em http://www.Pnud.org.br/arquivos/ranking-idhm-2010-uf.pdf 
Figura 2 - IDH-M Educação e IDH-M Longevidade do Brasil por UF
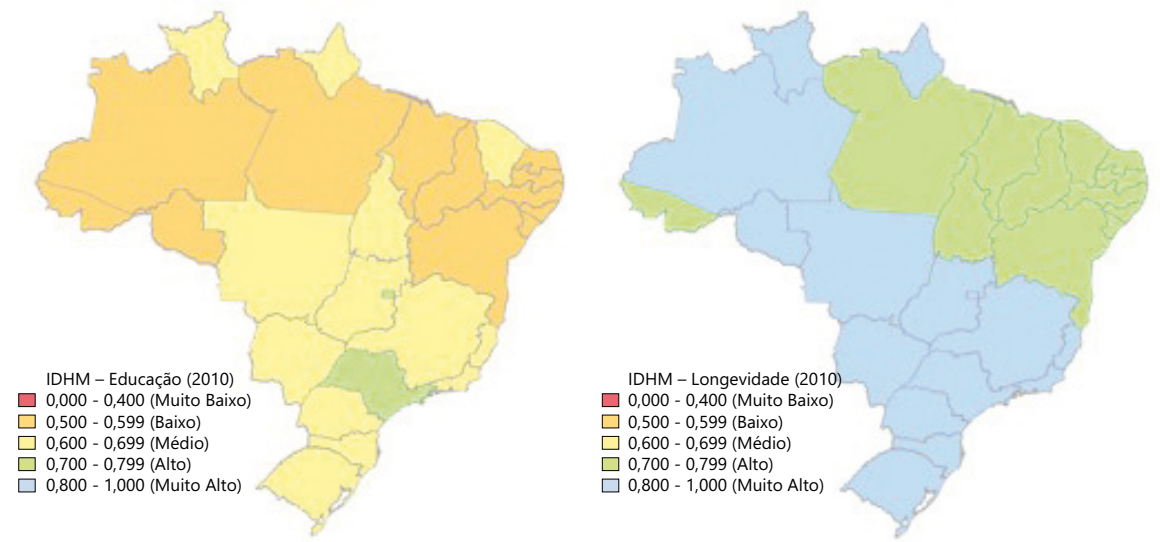

Fonte: Elaboração própria a partir do software QGis e dados do Pnud (ATLAS DO DESENVOLVIMENTO HUMANO NO BRASIL, 2018).

Na Figura 2, retratam-se o IDH-M Educação dos estados brasileiros, à esquerda, e o IDH-M Longevidade, à direita. Diferentemente do observado nas Figuras 1 e 2, o que se tem agora são dissemelhanças, com a primeira figura indicando um predomínio de baixo desenvolvimento no que tange à Educação e a segunda figura indicando elevados níveis de desenvolvimento quando o quesito é a longevidade dos brasileiros.

Há muitos fatores educacionais a serem considerados quanto ao desenvolvimento equitativo em Santa Catarina. Os dados deste estado mostram que a taxa de reprovação dos anos iniciais do Ensino Fundamental era de 3,6\%, em 2013, e passou para 2,9\%, em 2017; nos anos finais do Fundamental, essa taxa era de 11,2\%, em 2013, e passou para 9,8\%, em 2017; já no Ensino Médio, a taxa de reprovação era de 13,6\%, em 2013, e passou para 14,1\%, em 2017. Somente o Ensino Médio aumentou suas taxas de reprovação, que eram de $8,4 \%$, em 2006, e de $14,1 \%$, em 2017 (aumento médio de $8 \%$ ao ano). A Taxa de analfabetismo no estado, em 2017 , era de $0,6 \%$ para crianças de 10 a 14 anos e de 3,4\% para 15 anos ou mais. Em 2006, essas taxas eram, respectivamente, de $0,4 \%$ e $5,1 \%$.

Analisando o nível de desenvolvimento de Santa Catarina, percebe-se, a partir da Figura 3, à esquerda representando o IDH-M dos municípios catarinenses, que a maioria dos municípios encontra-se na faixa de alto desenvolvimento, alguns de 
médio desenvolvimento e poucos de desenvolvimento muito alto. Já na Figura 3, à direita, que representa o IDH-M Educação, podem-se encontrar municípios com indicativo de desenvolvimento muito baixo, sendo a maioria classificada como de baixo e de médio desenvolvimento. Poucos municípios constam como de alto desenvolvimento - somente Florianópolis caracteriza-se com desenvolvimento muito alto em Educação. Em se tratando do IDH-M renda, apresentado na Figura 4, à esquerda, o nível de desenvolvimento equipara-se ao IDH-M. Já no que tange ao IDH-M longevidade, Figura 4, à direita, há predominância de municípios considerados de desenvolvimento muito alto.

Percebe-se que há um movimento demográfico de queda no número de crianças e de adolescentes e aumento da população adulta, compensando o aumento da população total. No ano 2000, as crianças de 0 a 3 anos eram 377.471; de 4 a 6 anos, 302.063; de 7 a 14 anos, 829.949 e de 15 a 17 anos, 319.694, totalizando em 1.451 .706 a população em idade escolar. Já no ano de 2017, eram 320.798 (0 a 3 anos); 255.727 (4 a 6 anos), 785.788 ( 7 a 14 anos), 326.188 ( 15 a 17 anos) e a população em idade escolar passou a ser de 1.367.703. O percentual de população em idade escolar (4 a 17 anos) sobre a população total passou, então, de 27,1\%, em 2000, para 21,9\%, em 2017. Efetivamente, depreende-se uma queda no total das matrículas no Ensino Fundamental e Médio da ordem de aproximadamente 5,8\%, nos 10 anos avaliados, ratificando-se uma queda das matrículas em todas as faixas etárias.

Figura 3 - IDH-M e IDH-M Educação dos municípios de SC
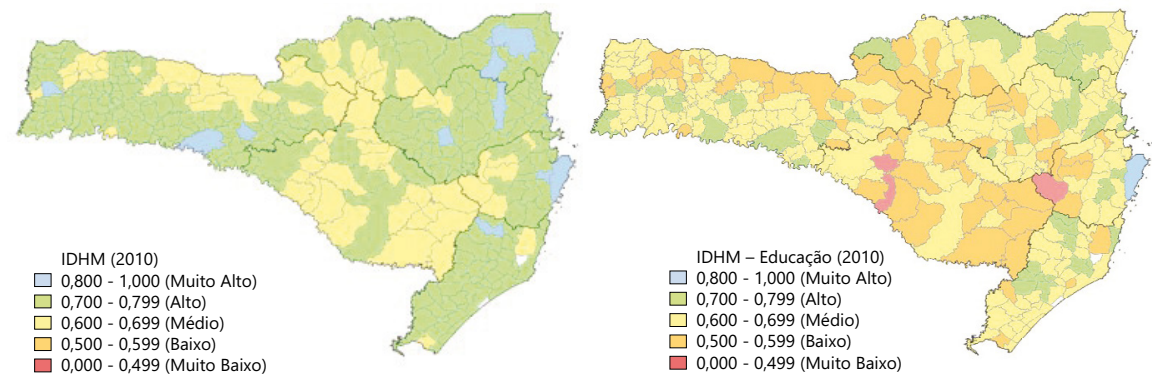

Fonte: Elaboração própria a partir do software QGis e dados do Pnud (ATLAS DO DESENVOLVIMENTO HUMANO NO BRASIL, 2018). 
Figura 4 - IDH-M Renda e IDH-M Longevidade dos municípios de SC
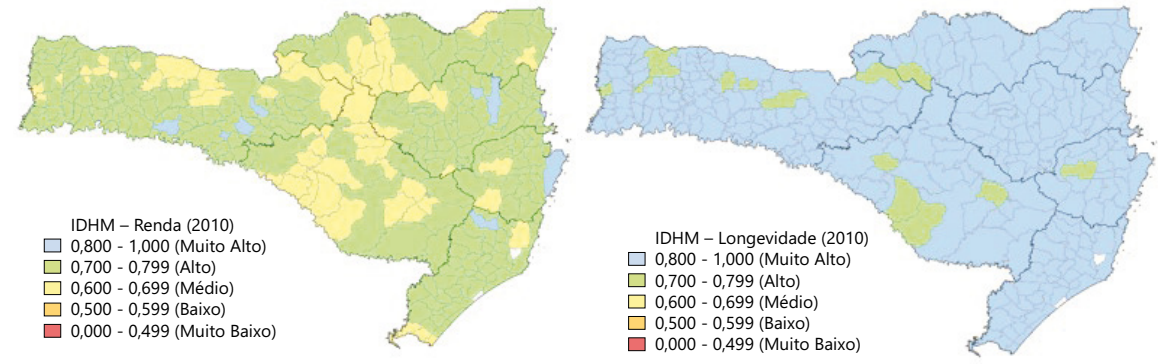

Fonte: Elaboração própria a partir do software QGis e dados do Pnud (ATLAS DO DESENVOLVIMENTO HUMANO NO BRASIL, 2018).

Pretende-se, com este trabalho, focar nesse debate, fazendo um estudo sobre as escolas de Santa Catarina. Postula-se debater a realidade educacional catarinense e produzir subsídios que possibilitem a formulação e a implementação de políticas públicas educacionais focalizadas, que busquem melhorar o desempenho das escolas e diminuir as desigualdades sociais no longo prazo.

Considerando a Educação como um dos principais fatores que influenciam a desigualdade de renda, objetiva-se, com esta pesquisa, analisar o impacto da Educação Superior nos ganhos em renda em Santa Catarina. A partir da análise dos dados da Relação Anual de Informações Sociais (Rais) para o período de 2006 a 2017, objetiva-se analisar os retornos à Educação, para o caso catarinense, e o incremento de renda incorporado a cada ano de estudo na vida do trabalhador formal.

\section{Referencial teórico}

Para estabelecer uma distinção entre crescimento e desenvolvimento econômico, Fonseca (2006) destaca que desenvolvimento econômico traduz-se em acumulação de recursos, crescimento da produção e das remunerações obtidas. Um dos fatores que mais contribui para o desenvolvimento econômico é a Educação. Isso porque a Educação é o elemento central do desenvolvimento de uma sociedade e sua importância ultrapassa os aspectos econômicos. O autor afirma que "privar um indivíduo de uma Educação de qualidade é condená-lo, com a sociedade a que ele pertence, ao subdesenvolvimento" (FONSECA, 2006, p. 8-9). 
Para Souza (2009), o desenvolvimento econômico pode ser definido como crescimento econômico contínuo acima do crescimento demográfico. O Índice de Desenvolvimento Humano é responsável por medir o nível de desenvolvimento dos países, regiões e municípios. O IDH é calculado a partir da média simples de três componentes: longevidade, Educação e nível de renda. $\mathrm{O}$ IDH varia de 0 a 1: sendo desenvolvimento humano baixo (IDH $\leq 0,499)$; desenvolvimento humano médio $(0,5 \leq \mathrm{IDH} \leq 0,799)$; desenvolvimento humano alto (IDH $\geq 0,800$ ).

Percebe-se que, para esses autores, a Educação está intimamente vinculada ao desenvolvimento econômico. O nível educacional possui relação direta com o nível de renda, e a renda possibilita o aumento do bem-estar, do consumo e do PIB. Não obstante, pode haver um problema de endogeneidade, uma vez que, indubitavelmente, a Educação impacta o desenvolvimento econômico, mas o contrário também é válido.

Para a análise do desenvolvimento econômico de Santa Catarina, além de comparar o IDH dos municípios, é necessário analisar a distribuição do rendimento salarial médio e da escolaridade média. A partir do cálculo do Gini de renda e do Gini educacional, indicadores que medem o nível de igualdade em sua distribuição, é possível estimar o nível de desenvolvimento catarinense com base nesses indicadores. Essas variáveis, quando calculados seus índices de Gini, permitem que se tornem comparáveis, e que com isso, se consiga estimar o grau de correlação entre elas.

O rendimento médio do trabalho, de acordo com Jannuzzi (2006), ou renda média, é um indicador que indica a remuneração recebida dividida pelo número de períodos considerados. Ainda de acordo com Jannuzzi (2006), o indicador de escolaridade média é calculado a partir da média dos anos estudados ponderados pela população.

Quanto à relação entre Educação e desenvolvimento econômico, Baptista Filho (1975) afirma que a Educação para o desenvolvimento constitui uma estratégia, pois direciona-se à formação de recursos humanos aptos a participar da força de trabalho. Segundo ele, "as diretrizes da Educação no Brasil sublinham a qualificação para o trabalho como meta social" (BAPTISTAFILHO, 1975, p. 55). O autor ainda afirma que educar é desenvolver, ou seja, educar é aumentar a renda, é ampliar o bem-estar social e conferir padrão de vida mais alto à população. Define que o desenvolvimento econômico e a obtenção de rendas mais altas caracterizam-se como recurso para incrementar a escolaridade. 
Barros, Henriques e Mendonça (2001) afirmam que o Brasil vive uma perversa simetria social, em que os $10 \%$ mais ricos apropriam-se de $50 \%$ da renda total, enquanto os $50 \%$ mais pobres dividem os $10 \%$ restantes. Para os autores, políticas que estimulem uma maior distribuição de renda podem ter efeitos maiores sobre a diminuição da pobreza do que políticas focalizadas em diminuir a quantidade de pobres, propriamente ditos.

Ramos e Mendonça (2005) afirmam que o debate acerca da desigualdade de renda iniciou-se na década de 1970, quando Langoni (2005) identificou a Educação como a variável mais importante para tentar explicar a desigualdade social. Os autores demonstram que, ao se analisar as contribuições para a desigualdade advinda do mercado de trabalho, a heterogeneidade educacional responde por uma parcela ainda maior da desigualdade de renda (52\%). Isto porque "o mercado de trabalho brasileiro é um revelador de desigualdades e não um gerador de desigualdades" (RAMOS; MENDONÇA, 2005, p. 372).

Ferreira (2000) aponta que o nível de Educação dos indivíduos responde por grande parcela da desigualdade de renda. Dependendo da análise, o nível educacional pode responder por $30 \%$ a $50 \%$ da desigualdade, o gênero fica responsável por cerca de $5 \%$ e a variável cor da pele, responsável por cerca de $2 \%$ da desigualdade de renda.

Ferreira e Veloso (2005) salientam que, comparando o Brasil com os Estados Unidos, no primeiro país, a Educação responde por $34 \%$ a $48 \%$ da desigualdade de renda, enquanto nos Estados Unidos, a Educação varia entre 3\% e 16\% do índice de Gini. Os autores também salientam a importância do nível de escolaridade dos pais como fator que influencia a escolaridade dos filhos e do nível de renda desses no longo prazo. Apontam que as chances de um filho de pai analfabeto concluir o Ensino Superior são de 0,6\%. Se o pai possuir Ensino Superior, a chance de esse filho também cursar o Ensino Superior passa para $60 \%$.

Pereira et al. (2016), apontam que, apesar do aumento no número de pessoas com Ensino Superior, percebe-se desvalorização da mão de obra qualificada, e afirmam que a remuneração deveria aumentar juntamente com o aumento na qualificação do trabalhador. Salientam a importância de projetos do governo que estimulem o acesso às universidades, fortalecendo a interação entre universidade, governo e empresas. Concluem que o mercado de trabalho não está preparado para absorver a maior parte dos trabalhadores que saem das universidades. Os autores evidenciam desvalorização da mão de obra, o que seria condizente com nosso estudo que evidencia retornos decrescentes de renda com relação à escolaridade. 
A importância da Educação Superior é tão evidente, que, conforme demonstrado por Gramani (2017), os próprios professores que possuem formação superior e Pós-Graduação geram efeito potencializado sobre o desenvolvimento econômico, uma vez que sua influência sobre os determinantes da Educação e sobre a formação dos alunos é maior. A Educação, além de gerar os efeitos de longo prazo sobre a renda futura dos alunos, gera efeito potencial de curto prazo sobre a qualidade socioeconômica dos municípios. Mas a Educação não pode ser vista como variável isolada, deve-se combinar com outras variáveis socioeconômicas que contribuam para o aperfeiçoamento da qualidade educacional e dos retornos à Educação.

Considerando essa relação entre nível educacional e desenvolvimento econômico, pretende-se avaliar o nível de desigualdade gerada pela escolaridade, cujos impactos afetam diretamente os ganhos salariais aumentando a desigualdade de renda e o desenvolvimento de longo prazo. Alguns dos propósitos deste artigo são: explicar porque bons rankings de desenvolvimento não revelam disparidades de renda, o quanto a Educação Superior incrementa a renda dos indivíduos e se há incentivo (se existir) para que os trabalhadores cursem Graduação (e Pós-Graduação), dados os retornos salariais que dela advém.

Para isso, torna-se necessário estimar dois indicadores de desigualdade: índice de Gini para desigualdade de renda e índice de Gini para distribuição educacional da população catarinense. Esses indicadores permitem analisar a variação na desigualdade de renda e de desigualdade educacional nos últimos anos (2006 a 2017), além de permitir identificar os diferenciais de renda média por faixas de escolaridade.

\section{Procedimentos metodológicos}

A pesquisa realizada caracteriza-se, preponderantemente, como quantitativa. Utilizando-se dos dados de Educação por faixa de escolaridade e de renda média nominal dos trabalhadores da Rais, busca-se estimar tanto o Gini de renda quanto o Gini de Educação de Santa Catarina, afim de mensurar a evolução desses dois indicadores e ver em que medida acontecem variações conjuntas, sejam elas inversamente ou diretamente proporcionais. Os dados de renda a serem utilizados compreendem os anos de 2006 a 2017 e foram deflacionados pelo Índice de Preços do Consumidor Amplo (IPCA). Tal intervalo ratifica-se pelo fato de, a partir de 2006, o Instituto Nacional de Estudos e Pesquisas Educacionais Anísio Teixeira (Inep) ter adotado essa metodologia para análise, considerando o Ensino Fundamental composto por nove anos, quando, nos anos anteriores, compreendia oito anos de interstício. 
O principal indicador de desigualdade de renda é o índice de Gini. Na definição de Jannuzzi (2006), o índice de Gini pode ser calculado a partir de dados de renda em intervalos de classe. As informações sobre renda podem se referir a renda familiar, renda per capita ou renda do trabalho. A medida assume um valor mínimo de zero, situação de igualdade perfeita da distribuição, e valor máximo de um, situação de extrema desigualdade.

Adotando-se a metodologia utilizada por Hoffmann (2009) para o cálculo do Gini de renda, utilizou-se como população os dados de todos os trabalhadores cadastrados na Rais em Santa Catarina, que foram agrupados em 10 percentis. Classificando-se a população adotada em decis de renda, pode-se obter a porcentagem acumulada da renda média para cada intervalo de classe. Tomando como $P$ o valor da população acumulada e $W$ o valor da renda acumulada, podese estimar a área da curva de Lorenz a partir da soma da frequência, dada por $F i$, de cada variável para se obter o nível de desigualdade.

Os valores de $P$ e $W$ são dados por:

$$
\begin{aligned}
& P=\sum_{i=1}^{n} F i . p n \\
& W=\sum_{i=1}^{n} F i . W n
\end{aligned}
$$

A curva de Lorenz é obtida pela plotagem dos valores acumulados de $P$ e de $W$. O índice de Gini, por sua vez, é obtido a partir da razão entre a área da curva de Lorenz dividida por 0,5 (área de um triângulo retângulo com base 0 e altura de valor 1 - que são os valores mínimo e máximo do índice de Gini). Definindo-se como $\alpha$ o valor da área da curva de Lorenz que se encontra abaixo da linha de perfeita igualdade, o índice de Gini é definido por:

$$
\text { Gini }=\frac{\alpha}{0,5}
$$

Para uma distribuição discreta, o valor do Gini pode ser obtido do seguinte modo: tomando uma situação de $n$ estratos de população ordenados em ordem crescente de renda, obtém-se os valores acumulados da renda dos $n$ estratos e pode-se calcular a frequência $F i$ de cada renda $W_{\mathrm{i}}$ associada a cada estrato da população $P_{\mathrm{i}}$. A partir da frequência acumulada das rendas, pode-se obter o valor do Gini da seguinte maneira:

$$
\operatorname{Gini}_{\text {Renda }}=1-\left(\frac{1}{n}\right) \sum_{i=1}^{n} W i . F i
$$


Quanto à metodologia adotada para o cálculo do Gini educacional, conforme proposto por Thomas, Wang e Fan (2001), em vez dos percentis, passam-se a considerar as faixas de escolaridade, de acordo com categorização adotada pelo Inep. Neste sentido, considerando-se Gini Educação como o índice de Gini Educacional, o cálculo do coeficiente é obtido por:

$$
\operatorname{Gini}_{\text {Educação }}=\left(\frac{1}{\mu}\right) \sum_{i=2}^{n} \sum_{j=1}^{i-1} p i(y i-y j) p l
$$

Onde:

- $\mu$ é a escolaridade média, que é calculada por $\mu=\sum_{i=1}^{n}$ piyi

- pi e pj é a proporção de pessoas por nível de escolaridade; e yi e yj os anos de escolaridade média em cada faixa de escolaridade; $n$ é o número de faixas de escolaridade.

Foram consideradas as seguintes faixas de escolaridade e anos médios de estudo:

- Analfabeto $=0$ anos de estudo;

- Até $5^{\circ}$ incompleto $=2,5$ anos de estudo;

- $5^{\circ}$ completo $=5$ anos de estudo;

- $6^{\circ}$ a $9^{\circ}$ fundamental $=7,4$ anos de estudo;

- Fundamental completo $=9$ anos de estudo;

- $\quad$ Médio incompleto = 11 anos de estudo;

- Médio completo = 12 anos de estudo;

- Superior incompleto (para cursos de 5 anos) $=15$ anos de estudo;

- Superior completo (para cursos de 5 anos) = 17 anos de estudo;

- $\quad$ Mestrado = 19 anos de estudo;

- $\quad$ Doutorado $=23$ anos de estudo. 
Como escala para o índice de Gini, tanto de renda quanto de Educação, considerou-se de 0 a 0,250 como muito baixo; de 0,251 a 0,500 como baixo; de 0,501 a 0,750 como médio; de 0,751 a 0,800 como alto; e de 0,801 a 1,000 como muito alto.

\section{Evolução educacional em Santa Catarina}

A população de Santa Catarina vem aumentando gradativamente. Nos últimos 10 anos, a população total passou de 5.980.986 habitantes, em 2006, para 7.075.494 habitantes, em 2018, representando aumento de $17 \%$, para o período, e de $1,8 \%$ ao ano. Não obstante o crescimento da população em geral, percebe-se mudança na pirâmide etária da população do estado. Enquanto a população aumentava como um todo, o número de crianças e de jovens vem caindo gradativamente, conforme mostra o Gráfico 1.

Gráfico 1 - Evolução da população de Santa Catarina por faixas de idade

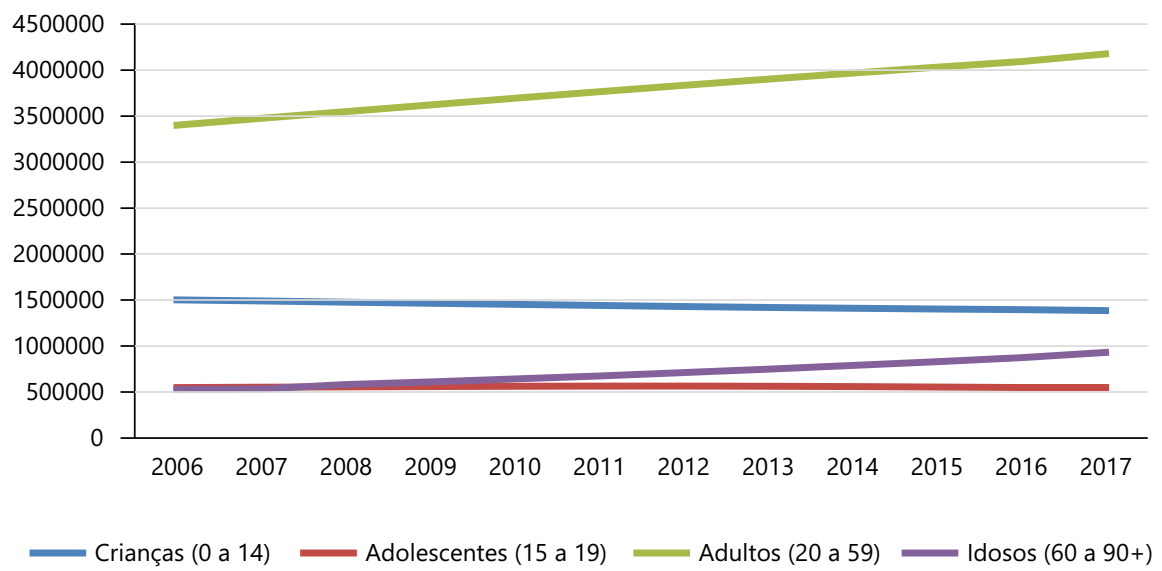

Fonte: Relação Anual de Informações Sociais, 2016

A modificação da pirâmide etária nos últimos 11 anos evidencia o encurtamento nas faixas de menores idades e expansão nas maiores faixas etárias. Essa movimentação muda o formato de mais triangular observado em 2006 (Figura 5, à esquerda) para formato mais arredondado com maior expressividade no centro (Figura 5, à direita). Em 2006 as crianças de 0 a 4 anos representavam $8 \%$ da população, já em 2017, eram 5\%; as crianças de 5 a 9 anos representavam $8 \%$ da população, em 2006, passando para 6,5\%, em 2017; as de 10 a 14 anos eram 9\% e caíram para $6 \%$; e de 15 a 19 anos eram $9 \%$, passando para $7,5 \%$. 
Figura 5 - Pirâmide etária de SC em 2006 e Pirâmide etária de SC em 2017

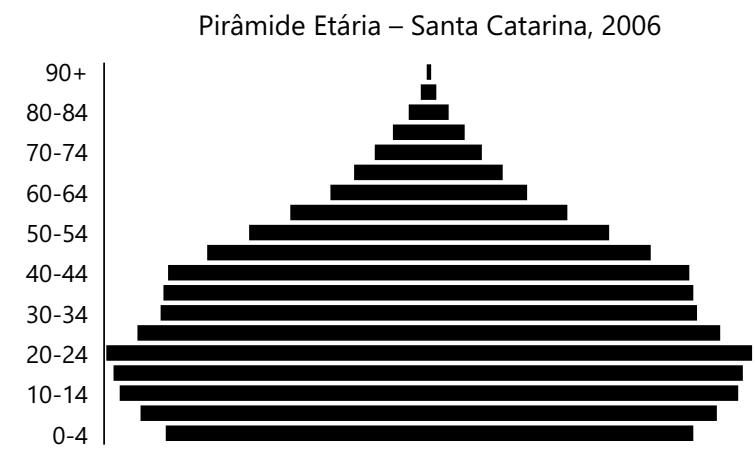

Pirâmide Etária - Santa Catarina, 2015

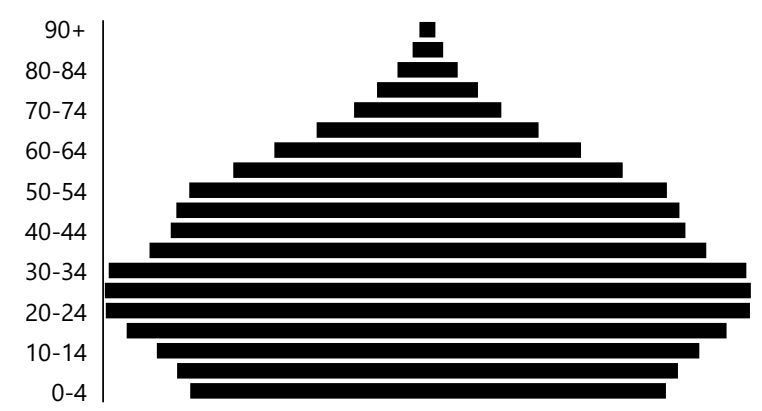

Fonte: IBGE, 2018

Crianças e jovens de 0 a 19 anos somavam 34\% de participação na população em 2006 e passaram a responder por $28 \%$ da população em 2017. A população de 20 a 59 anos somava $56,9 \%$ em 2006 e passou para 59,7\% em 2017. Já a população de 60 a 90 anos ou mais passou de 8,8\% em 2006 para 13,5\% em 2017.

O número de matrículas vem apresentando quedas sucessivas em praticamente todos os anos. O número de crianças matriculadas na creche, em 2006, era de 77.101 e passou para 152.835 em 2017. Na Pré-Escola, eram 166.160 crianças matriculadas, em 2006, e 159.923 em 2017. Passando para o Ensino Fundamental, nas séries iniciais havia 499.081 crianças em 2006, passando para 460.032 crianças em 2017; no Fundamental, nas séries finais, eram 452.111 crianças, em 2006, e 336.115 em 2017. Com relação ao Ensino Médio, em 2006, havia 269.594 jovens matriculados, passando para $283.521 \mathrm{em} \mathrm{2017,}$ conforme mostra o Gráfico 2. 
Gráfico 2 - Matrículas da Educação Básica em Santa Catarina

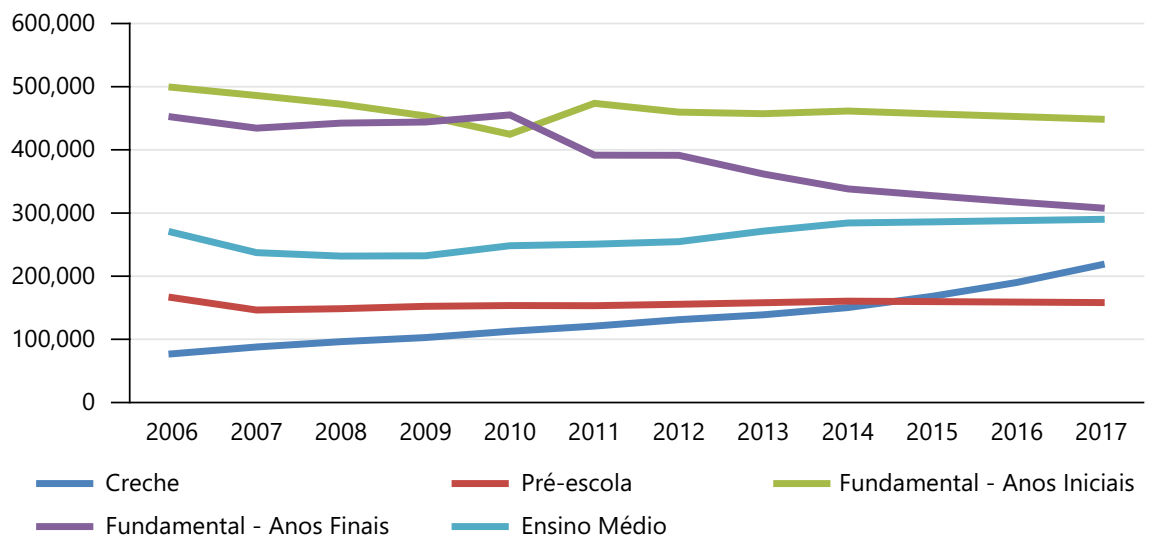

Fonte: INEP (2017).

Em que pese a divergência de evolução das faixas de ensino com características inversas, o desenho da pirâmide etária no estado de Santa Catarina evidencia um envelhecimento da população. Porém, há que se considerar a perspectiva de redução na faixa de reprovação e a melhoria na taxa de atendimento, aspectos favoráveis ao desenvolvimento. Por outro lado, mesmo com a diminuição da população-alvo, evidencia-se dificuldade em se atender a todas as crianças e adolescentes de forma a melhorar os resultados de aprovação. Considerando-se as Taxas de Aprovação (TAP), Taxas de Reprovação (TR) e Taxas de Abandono (TAB), percebe-se, para o Ensino Médio, não obstante a queda na taxa de abandono, aumento na taxa de reprovação, da ordem de 67\%, no período de 2006 a 2017. Mesmo com queda na população dessa faixa de escolaridade, a cobertura escolar encontra dificuldades em melhorar seus índices.

Tabela 1 - Evolução das Taxas de Aprovação, Reprovação e Abandono em Santa Catarina

\begin{tabular}{cccccccccc}
\hline & \multicolumn{3}{c}{ Fundamental Iniciais } & \multicolumn{3}{c}{ Fundamental Finais } & \multicolumn{3}{c}{ Ensino Médio } \\
\cline { 2 - 9 } & TAP & TR & TAB & TAP & TR & TAB & TAP & TR & TAB \\
\hline 2006 & 90,3 & 9 & 0,7 & 86 & 12,2 & 1,8 & 80,8 & 8,4 & 10,8 \\
2007 & 93,3 & 6,4 & 0,3 & 87,1 & 11,7 & 1,2 & 83,8 & 9,1 & 7,1 \\
2008 & 95 & 4,7 & 0,3 & 86,4 & 12,2 & 1,4 & 83,8 & 8,9 & 7,3 \\
2009 & 95,2 & 4,5 & 0,3 & 86,8 & 11,8 & 1,4 & 83,7 & 9,5 & 6,8 \\
2010 & 96 & 3,8 & 0,2 & 90,4 & 8,2 & 1,4 & 82,5 & 10,4 & 7,1 \\
\hline
\end{tabular}


continuação

\begin{tabular}{cccccccccc}
\hline & \multicolumn{3}{c}{ Fundamental Iniciais } & \multicolumn{3}{c}{ Fundamental Finais } & \multicolumn{3}{c}{ Ensino Médio } \\
\cline { 2 - 10 } & TAP & TR & TAB & TAP & TR & TAB & TAP & TR & TAB \\
\hline 2011 & 96,6 & 3,1 & 0,3 & 92,4 & 5,9 & 1,7 & 84,5 & 7,5 & 8 \\
2012 & 96,1 & 3,6 & 0,3 & 91,1 & 7,4 & 1,5 & 83 & 10,1 & 6,9 \\
2013 & 96,3 & 3,6 & 0,1 & 87,6 & 11,2 & 1,2 & 79 & 13,6 & 7,4 \\
2014 & 96,3 & 3,5 & 0,1 & 88,8 & 10,1 & 1,2 & 79,7 & 13,8 & 7,4 \\
2015 & 96,5 & 3,4 & 0,1 & 89,3 & 9,7 & 1 & 79,9 & 12,7 & 7,4 \\
2016 & 96,2 & 3,7 & 0,1 & 88,9 & 10,2 & 0,9 & 81,7 & 12,3 & 6 \\
2017 & 96,5 & 3,4 & 0,1 & 90,4 & 8,7 & 0,9 & 83,6 & 10,1 & 6,3 \\
\hline
\end{tabular}

Fonte: TODOS PELA EDUCAÇÃO (2018).

A taxa de abandono na Educação revela uma queda anual do abandono na Educação Básica e um crescimento no Ensino Médio, revelando um provável impacto na continuidade dos estudos pós-médio na faixa de 7,4\% dos estudantes no Ensino Médio.

Depreende-se que, mesmo com a queda no número de jovens e de crianças, tem se tornado mais difícil atingir patamares melhores de taxa de reprovação. Os dados levantados apontam para diversas dificuldades que o estado catarinense precisa enfrentar para estabelecer um padrão elevado de desenvolvimento sustentado, desenvolvimento esse que se encontra fragilizado frente aos problemas decorrentes da Educação, que, por muitas vezes, é ofuscado pelos demais indicadores.

\section{Análise dos resultados da pesquisa}

Os dados de renda média real (deflacionados pelo IPCA) mostram os ganhos reais em termos de anos de estudo. Esses valores, desagregados por faixa de escolaridade, mostram que, em 2017, um trabalhador que tinha Ensino Fundamental completo ganhava $13 \%$ a menos, em média, de salário que o trabalhador que não tinha escolaridade alguma (analfabeto). Quem tinha Ensino Médio completo ganhava $3 \%$ a mais que um trabalhador que tinha apenas o nível fundamental completo; para um trabalhador com nível superior completo, essa diferença podia chegar a $157 \%$ (salário 2,5 vezes maior) mais do salário de nível médio completo; com Mestrado, ganhava-se $40 \%$ mais que o profissional com nível superior completo; e com Doutorado, ganhava-se 1\% mais que o salário do trabalhador com Mestrado. A diferença maior observa-se quando a faixa de escolaridade passa de Ensino Médio completo para Ensino Superior completo, indicando os ganhos incrementais da formação superior no poder aquisitivo dos trabalhadores de Santa Catarina. 
Tabela 2 - Desigualdade, Educação e renda em Santa Catarina

\begin{tabular}{|c|c|c|c|c|c|c|c|c|c|c|}
\hline & $\begin{array}{c}\text { Gini } \\
\text { Renda }\end{array}$ & $\begin{array}{c}\text { Gini } \\
\text { Educação }\end{array}$ & $\begin{array}{l}\text { Renda } \\
\text { Média }\end{array}$ & Escolaridade & Analfabeto & Fundamental & $\begin{array}{l}\text { Ensino } \\
\text { Médio }\end{array}$ & Superior & Mestrado & Doutoradc \\
\hline 2006 & 0,532 & 0,405 & 1.037 & 10,78 & 562 & 721 & 916 & 2.345 & 2.985 & 4.693 \\
\hline 2007 & 0,537 & 0,414 & 1.091 & 10,94 & 577 & 750 & 918 & 2.358 & 3.644 & 5.770 \\
\hline 2008 & 0,534 & 0,421 & 1.184 & 11,07 & 613 & 802 & 962 & 2.512 & 3.849 & 5.381 \\
\hline 2009 & 0,534 & 0,428 & 1.274 & 11,17 & 721 & 876 & 1.033 & 2.782 & 4.238 & 5.814 \\
\hline 2010 & 0,536 & 0,434 & 1.399 & 11,28 & 744 & 952 & 1.107 & 2.980 & 4.073 & 3.516 \\
\hline 2011 & 0,544 & 0,439 & 1.535 & 11,38 & 846 & 1.037 & 1.200 & 3.205 & 4.127 & 4.190 \\
\hline 2012 & 0,545 & 0,447 & 1.704 & 11,50 & 930 & 1.141 & 1.319 & 3.565 & 4.591 & 4.908 \\
\hline 2013 & 0,542 & 0,452 & 1.865 & 11,60 & 1.208 & 1.254 & 1.436 & 3.763 & 4.950 & 5.382 \\
\hline 2014 & 0,546 & 0,458 & 2.047 & 11,74 & 1.327 & 1.388 & 1.558 & 3.998 & 5.373 & 6.435 \\
\hline 2015 & 0,548 & 0,465 & 2.296 & 11,87 & 1.553 & 1.549 & 1.694 & 4.350 & 5.910 & 6.734 \\
\hline 2016 & 0,550 & 0,473 & 2.606 & 12,00 & 1.857 & 1.746 & 1.855 & 4.764 & 6.554 & 7.059 \\
\hline 2017 & 0,551 & 0,481 & 3.000 & 12,14 & 2.285 & 1.994 & 2.045 & 5.255 & 7.337 & 7.415 \\
\hline
\end{tabular}

Fonte: BRASIL, 2018

O índice Gini de renda é considerado médio para o estado de Santa Catarina. Seus patamares apontavam para nível de desigualdade de 0,532, em 2006, sofrendo aumento para 0,551, em 2017. No que tange ao índice de Gini educacional, Santa Catarina pode ser considerado como de baixa desigualdade, uma vez que, mesmo sofrendo aumento de 0,405 em 2006 para 0,481 em 2017, situa-se abaixo da faixa limítrofe de 0,500. Depreende-se, desta análise, que o nível de desigualdade educacional do estado é menor que a desigualdade de renda.

A Figura 6 retrata o Gini educacional, à esquerda, em 2006, e, à direita, o mesmo indicador, em 2017. Na Figura 6, é possível identificar quatro municípios com nível de desigualdade muito baixos em 2006 (Calmon com Gini educacional de 0,217; Monte Carlo com 0,229; Lebon Régis com 0,246; e Timbó Grande com 0,248). Para 2017, na figura da direita, não há nenhum município com desigualdade educacional muito baixa, a maioria é considerada de baixa desigualdade e destacam-se cinco municípios classificados como de média desigualdade educacional (Iraceminha com 0,509; Itapoá com 0,517; Tigrinhos com 0,528; Abdon Batista com 0,532 e Florianópolis com 0,558).

No que tange ao Gini de renda, assim como acontece para o Gini educacional, na Figura 7, à esquerda, em 2006, é possível perceber alguns municípios classificados como desigualdade de renda muito baixa em azul (Painel com Gini 
de 0,226; Brunópolis com 0,241; e Entre Rios com 0,246); na Figura 7, à direita, para o ano de 2017, nenhum município apresentava-se como de desigualdade muito baixa, embora o equivalente a baixa desigualdade tenha também diminuído (com média desigualdade, em amarelo, destacam-se Jaraguá do Sul com 0,506; Capivari de Baixo com 0,514; Botuverá com 0,517; São Francisco do Sul com 0,571; Treviso com 0,596; e Florianópolis com 0,667 no Gini de renda).

A escolaridade média dos trabalhadores formais de Santa Catarina, traduzida pela média dos anos de estudo, era de 10,78 anos de estudo em 2006, e passou para 12,14 anos em 2017 (aumento de 9,1\%). Já o número de trabalhadores formais passou de 1.598.454, em 2006, para 2.205.738, em 2017 (aumento de 43\%). A renda média real (média de todos os trabalhadores) era de $\mathrm{R} \$ 1.037$, em 2006, e passou para R \$3.000, em 2017 (aumento de 147\%, para o período, e de 13,9\% ao ano).

Figura 6 - Índice de Gini educacional por município de SC em 2006 e Índice de Gini educacional por município de SC em 2017
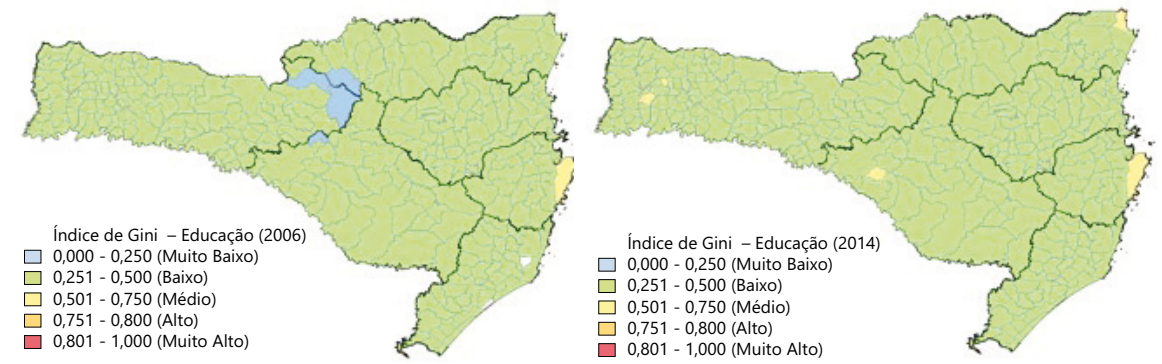

Fonte: Elaboração própria a partir do software QGis e dados da RAIS (BRASIL, 2018)

Figura 7 - Índice de Gini de renda por município de SC em 2006 e Índice de Gini de renda por município de SC em 2017
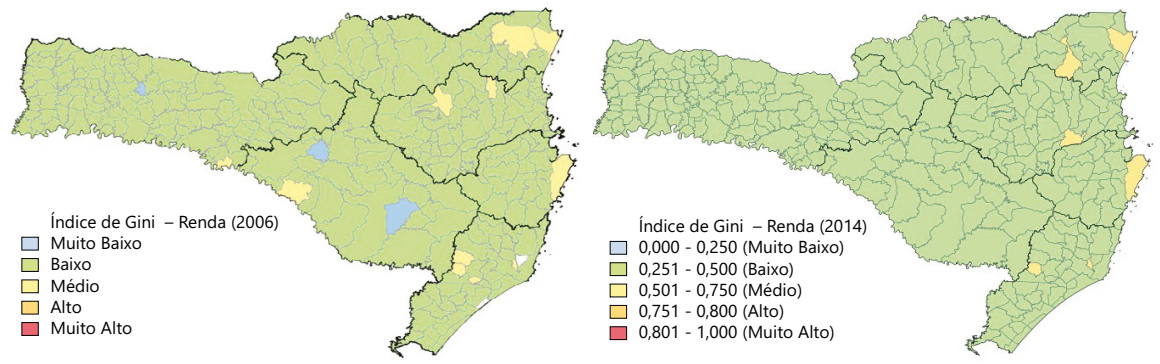

Fonte: Elaboração própria a partir do software QGis e dados da RAIS (BRASIL, 2018) 
Neste sentido, a média de salário de um profissional com Ensino Médio completo é $15 \%$ superior à de um profissional analfabeto. Porém, quando comparado com um profissional com Ensino Superior, a faixa salarial é, em média, 162\% superior ao do Ensino Médio; a do Mestrado é 38\% maior que a do Ensino Superior e a do Doutorado é $20 \%$ maior que a do Mestrado. O incremento adicional entre as faixas de escolaridade fica mais bem evidenciado na Tabela 3.

Tabela 3 - Diferença percentual do incremento salarial por faixa de escolaridade

\begin{tabular}{lccccc}
\hline & $\begin{array}{c}\text { Analfabeto para } \\
\text { Fundamental }\end{array}$ & $\begin{array}{c}\text { Fundamental } \\
\text { para Médio }\end{array}$ & $\begin{array}{c}\text { Médio para } \\
\text { Superior }\end{array}$ & $\begin{array}{c}\text { Superior para } \\
\text { Mestrado }\end{array}$ & $\begin{array}{c}\text { Mestrado para } \\
\text { Doutorado }\end{array}$ \\
\hline 2006 & $28 \%$ & $27 \%$ & $156 \%$ & $27 \%$ & $57 \%$ \\
2007 & $30 \%$ & $22 \%$ & $157 \%$ & $55 \%$ & $58 \%$ \\
2008 & $31 \%$ & $20 \%$ & $161 \%$ & $53 \%$ & $40 \%$ \\
2009 & $21 \%$ & $18 \%$ & $169 \%$ & $52 \%$ & $37 \%$ \\
2010 & $28 \%$ & $16 \%$ & $169 \%$ & $37 \%$ & $-14 \%$ \\
2011 & $23 \%$ & $16 \%$ & $167 \%$ & $29 \%$ & $2 \%$ \\
2012 & $23 \%$ & $16 \%$ & $170 \%$ & $29 \%$ & $7 \%$ \\
2013 & $4 \%$ & $15 \%$ & $162 \%$ & $32 \%$ & $9 \%$ \\
2014 & $5 \%$ & $12 \%$ & $157 \%$ & $34 \%$ & $20 \%$ \\
2015 & $0 \%$ & $9 \%$ & $157 \%$ & $36 \%$ & $14 \%$ \\
2016 & $-6 \%$ & $6 \%$ & $157 \%$ & $38 \%$ & $8 \%$ \\
2017 & $-13 \%$ & $3 \%$ & $157 \%$ & $40 \%$ & $1 \%$ \\
\hline
\end{tabular}

Fonte: RAIS (BRASIL, 2018).

Assim, considerando-se os dados coletados na pesquisa, os incrementos salariais entre as faixas de escolaridade, no caso de Santa Catarina, revelam-se marginais, quando se compara o Ensino Médio com o Fundamental e o Fundamental com o nível de analfabetos. Entretanto, na relação entre o Ensino Superior e o Ensino Médio, o incremento é, em todos os anos, superior a $150 \%$, demonstrando a valorização deste nível de escolaridade no mercado de trabalho no estado. As faixas salariais da Pós-Graduação apresentam incrementos significativos na comparação entre elas e o Ensino Superior, ainda que em menor grau.

Percebe-se, desde 2006, uma maior concentração de pessoas com Ensino Médio completo. Mesmo considerando o aumento do número de pessoas com nível superior completo, a concentração de pessoas com Ensino Médio passa de 32,32\%, 
em 2006, para 49,1\%, em 2017; em 2006 eram 12,6\% com Ensino Superior completo e, em 2017, eram 17,9\%. O incremento do Ensino Médio foi de 35,0\%, enquanto o incremento do Ensino Superior, para o mesmo período, foi de 30,0\%. O contingente com Pós-Graduação era de $0,24 \%$ dos trabalhadores, em 2006, e, em 2017, era de 1,9\% (aumento de $680 \%$ vezes o valor inicial), conforme Tabela 4. Mesmo que tenha aumentado o contingente de trabalhadores com nível superior, conforme explicitam Lameiras e Vasconcelos (2018), nem sempre esse grupo consegue obter uma função compatível com seu grau de instrução.

Tabela 4 - Composição Educacional de Santa Catarina (em percentual)

\begin{tabular}{lcccccccccccc}
\hline & $\mathbf{2 0 0 6}$ & $\mathbf{2 0 0 7}$ & $\mathbf{2 0 0 8}$ & $\mathbf{2 0 0 9}$ & $\mathbf{2 0 1 0}$ & $\mathbf{2 0 1 1}$ & $\mathbf{2 0 1 2}$ & $\mathbf{2 0 1 3}$ & $\mathbf{2 0 1 4}$ & $\mathbf{2 0 1 5}$ & $\mathbf{2 0 1 6}$ & $\mathbf{2 0 1 7}$ \\
\hline Analfabeto & 0,3 & 0,3 & 0,3 & 0,3 & 0,3 & 0,2 & 0,2 & 0,3 & 0,3 & 0,3 & 0,3 & 0,3 \\
$\begin{array}{l}\text { Até 5 } \\
\text { Incompleto }\end{array}$ & 2,3 & 2,3 & 2,3 & 2,2 & 2,3 & 2,3 & 2,1 & 2,1 & 2 & 2,0 & 1,9 & 1,9 \\
$\begin{array}{l}5^{\text {C Completo }} \\
\text { Fundamental }\end{array}$ & 7,6 & 7 & 6,4 & 5,7 & 5,2 & 4,8 & 4,3 & 3,9 & 3,6 & 3,4 & 3,2 & 3,0 \\
$\begin{array}{l}\text { 6 a 9a } \\
\text { Fundamental }\end{array}$ & 10,8 & 10,1 & 9,3 & 8,5 & 8,1 & 7,6 & 7,1 & 6,9 & 6,5 & 6,2 & 5,9 & 5,7 \\
$\begin{array}{l}\text { Fundamental } \\
\text { Completo }\end{array}$ & 19,3 & 18,4 & 17,7 & 17 & 16,3 & 15,6 & 15 & 14,2 & 13,6 & 13,1 & 12,7 & 12,3 \\
$\begin{array}{l}\text { Médio } \\
\text { Incompleto }\end{array}$ & 9,7 & 9,5 & 9,3 & 9,1 & 9 & 8,8 & 8,6 & 8,4 & 8,2 & 8,0 & 7,9 & 7,8 \\
$\begin{array}{l}\text { Médio } \\
\text { Completo }\end{array}$ & 32,3 & 33,5 & 35,2 & 37,6 & 39,2 & 40,6 & 42 & 42,9 & 43,7 & 45,6 & 47,5 & 49,1 \\
$\begin{array}{l}\text { Superior } \\
\text { Incompleto }\end{array}$ & 4,5 & 4,5 & 4,6 & 4,7 & 4,6 & 4,6 & 4,6 & 4,5 & 4,5 & 4,5 & 4,5 & 4,5 \\
$\begin{array}{l}\text { Superior } \\
\text { Completo }\end{array}$ & 12,6 & 13,7 & 14,2 & 14 & 14,2 & 14,6 & 15,1 & 15,8 & 16,4 & 17,0 & 17,5 & 17,9 \\
$\begin{array}{l}\text { Mestrado } \\
\begin{array}{l}\text { Doutorado } \\
\hline\end{array}\end{array}$ & 0,2 & 0,2 & 0,1 & 0,2 & 0,2 & 0,3 & 0,3 & 0,4 & 0,5 & 0,6 & 0,7 & 1,2 \\
\hline Fonte: RAIS (BRASIL & 0,05 & 0,04 & 0,05 & 0,12 & 0,1 & 0,13 & 0,16 & 0,18 & 0,3 & 0,4 & 0,7 \\
\hline
\end{tabular}

Fonte: RAIS (BRASIL, 2018).

Ao se observar que as maiores diferenças salariais se encontram na fronteira entre o Ensino Médio e o Superior, é possível deduzir que a evolução da composição educacional catarinense se encontra comprometida com o aumento marginal de pessoas com Ensino Superior relativo ao percentual de pessoas com Ensino Médio. O percentual de pessoas com Educação Básica (que possuem, pelo menos, o Ensino Médio completo) passou de 49,6\% para 73,3\%, embora, o maior contingente se encontre no primeiro intervalo (Ensino Médio completo). Esses valores permitem inferir que a maior concentração de contingente populacional com Ensino Médio 
completo em detrimento ao Ensino Superior tende a aumentar ainda mais as diferenças salariais se considerada essa fronteira de faixa de escolaridade.

Barbosa Filho e Pessôa (2009) apontam que há forte relação positiva entre escolaridade e nível de renda. Quanto maior a desigualdade educacional, e mais o mercado de trabalho valorizar a qualificação pagando salários maiores, maiores também serão as desigualdades de renda. Em locais muito pobres, em que a população apresenta homogeneidade educacional muito baixa, incrementos na escolaridade podem provocar efeitos sobre o aumento na desigualdade de renda. Afirmam que enquanto a Educação explica de $35 \%$ a $50 \%$ da desigualdade de renda, o segundo fator mais relevante é a segmentação do mercado de trabalho, que responde por $5 \%$ a $15 \%$ da desigualdade salarial. Essa segmentação é identificada quando trabalhadores do mesmo sexo, mesma cor de pele e mesma escolaridade auferem remunerações diferentes explicadas pelo setor produtivo em que se encontram empregadas.

Ramos e Reis (2009) afirmam que, para pais que possuem, pelo menos, o Ensino Fundamental completo, um ano a mais de estudo proporciona $4,8 \%$ a mais de incremento salarial se comparado a filhos de pais que possuem, pelo menos, as séries iniciais do Fundamental. Concluem que indivíduos cujos pais cursaram as séries iniciais do Ensino Fundamental recebem, em média, 12\% a mais que indivíduos cujos pais não finalizaram esta etapa de ensino, enquanto a diferença salarial de pais que possuem o Ensino Fundamental completo passa a ser de 37\%.

\section{Considerações finais}

A pesquisa possibilitou concluir, considerando os dados dos trabalhadores cadastrados na Rais de Santa Catarina, um efetivo crescimento da renda média real auferida pelos trabalhadores entre 2006 e 2017, em todas as faixas de escolaridade avaliadas. Apesar do crescimento por faixa de escolaridade, entre 2006 e 2017, ser da ordem de 70\% para as faixas de Ensino Médio, Ensino Superior e Mestrado, contra apenas $37 \%$ de crescimento para a faixa de Doutorado. $\mathrm{Na}$ comparação do Ensino Médio com a faixa de analfabetos, o crescimento do nível de escolaridade importa em $137 \%$, no mesmo intervalo de anos, e de $92 \%$ para a faixa de Ensino Fundamental, os maiores salários estão efetivamente associados às maiores faixas de escolaridade.

Os incrementos salariais entre as faixas de escolaridade, no caso de Santa Catarina, revelam-se marginais, quando se compara o Ensino Médio com o Fundamental e o Fundamental com o nível de analfabetos. Entretanto, na relação entre o Ensino Superior e o Ensino Médio, o incremento é, em todos os anos, superior a 150\%, 
demonstrando a valorização deste nível de escolaridade no mercado de trabalho no estado. As faixas salariais da Pós-Graduação apresentam incrementos significativos na comparação entre elas e o Ensino Superior, ainda que em menor grau.

Embora muitas variáveis educacionais apontem para uma melhora no nível educacional do estado, tais como diminuição na taxa de abandono, queda na taxa de distorção idade-série e aumento da escolaridade média, outras variáveis apresentaram resultado oposto, comprometendo a qualidade da Educação catarinense, tais como aumento na taxa de reprovação e aumento na diferença salarial por faixa de escolaridade. Esses fatores repercutem negativamente sobre o desenvolvimento econômico do estado, suscitando aumento de desigualdades sociais, em especial as desigualdades educacional e de renda.

Depreende-se que elevados índices de desenvolvimento humano ocultam problemas pontuais que podem ser identificados ao se desagregar as variáveis que o compõem. Os problemas relativos à Educação e as diferenças de níveis de desenvolvimento, quando se compara Educação e longevidade, por exemplo, permitem inferir que esses tipos de desenvolvimentos díspares não podem ser considerados sustentados.

Tanto a escolaridade média, medida em anos de estudo, quanto a renda média real vêm aumentando gradativamente desde 2006. Entretanto, esses fatores não foram suficientes para amenizar os indicadores de desigualdade social, medidos pelo Gini de renda e pelo Gini educacional. Mesmo com aumento da escolaridade e da renda, a desigualdade vem aumentando, fato que possibilita inferir que a distribuição da escolaridade dentro das faixas influencia a desigualdade social. De modo análogo, a forma como a renda está distribuída também impacta na desigualdade, e pode ser constatada com grandes diferenciais nas fronteiras de faixas de escolaridade.

A pesquisa permite concluir que, como se espera, a renda aumenta quando se ultrapassa as fronteiras das faixas de escolaridade. Importa notar para os grandes diferenciais observados quando os trabalhadores passam do Ensino Médio completo para o Ensino Superior completo. Nessa situação, os incrementos salariais são da ordem de $156 \%$, quando se identifica que a média salarial dos trabalhadores com Ensino Superior é 2,5 vezes maior que o salário do trabalhador com apenas o Ensino Médio. Diferença dessa magnitude não pode ser percebida ao ultrapassar a fronteira da faixa de escolaridade para Mestrado ou Doutorado, cujo incremento caracteriza-se como potencialmente menor, ratificando-se o impacto que a Educação Superior possui sobre a renda dos trabalhadores no estado. Mesmo 
constatando a importância no Ensino Superior, pode-se perceber um movimento de maior concentração no sentido do nível educacional correspondente ao Ensino Médio completo, fato que pode acentuar ainda mais as diferenças salariais, não só entre Ensino Médio e Superior, mas entre as demais faixas de escolaridade.

Os incentivos, ao se ingressar num curso de nível superior são bastante atrativos, uma vez que, em média, a renda aumentará $162 \%$, possibilitando melhorias no bem-estar social, acesso a bens e a serviços, maiores possibilidades de acesso a saúde e a Educação. Percebe-se, então, que, em Santa Catarina, dados os retornos à Educação Superior, é possível identificar grandes vantagens em cursar uma Graduação, pois, certamente, haverá aumento marginal da renda maior que 150\%. A importância da Educação Superior se dá, no sentido de diminuição das disparidades de renda, melhorando os indicadores socioeconômicos e diminuindo os índices de Gini de renda e de Educação.

Os incentivos para cursar a Pós-Graduação, por outro lado, não são tão promissores quanto os incentivos de cursar a Graduação. Os retornos marginais da renda de Pós-Graduação são decrescentes no tempo, mostrando que, cada vez menos, o mercado de trabalho catarinense valoriza os trabalhadores com qualificação pós-graduada, de modo que podem ter que ser alocados em ocupações que exigem qualificação inferior. Além disso, em sua relação com a disparidade de renda, podem gerar distorções nos indicadores, aumentando o índice de Gini de renda, uma vez que o aumento na escolaridade média não acompanhará o aumento na renda média. Deste modo, o mercado de trabalho, ao não conseguir absorver todo o contingente graduado, e não estar preparado para receber profissionais com qualificação pós-graduada, acaba penalizando os profissionais mais capacitados, nivelando os salários por baixo. 


\title{
The importance of Higher Education in reducing income inequality in Santa Catarina
}

\begin{abstract}
The Santa Catarina state has the third position in ranking of HDI, a development grade appointed by the United Nations Development Program (UNDP). However, Santa Catarina education finds gaps that allow us to question the sustainable development. This research aims to analyze the importance of Higher Education that affect the long run development. Considering the Gini income and Gini educational grade is possible to conclude that the inequality of concentration indices allow us to think that the state does not have inequalities revealed by these meanings. The research shows that inequality has increased in the state and there are many differences in wage gains between high school and Higher Education exceeding 150\%. It is noticed an increasing trend of workers in high school in front of other educational groups.
\end{abstract}

Keywords: High Education. Inequality. Wages. Schooling, Gini Index.

\section{La importancia de la Educación Superior para reducir las disparidades de ingresos en Santa Catarina}

\section{Resumen}

El estado de Santa Catarina se encuentra en la tercera posición en el ranking de estados brasileños, considerando el IDH-M, en un documento señalado por el Pnud. Aunque este dato es favorable, la Educación en Santa Catarina encuentra brechas que nos permiten cuestionar el desarrollo sostenido. Esta investigación, con un enfoque cuantitativo, analiza la importancia de la Educación Superior en el desarrollo económico del estado. Esta investigación, con un enfoque cuantitativo, analiza la importancia de la Educación Superior en el desarrollo económico del estado. A partir del Gini de ingresos y el Gini educativo, calculado a partir de los datos de la Rais de Santa Catarina, entre 2006 y 2017, los índices de concentración de desigualdad permiten inferir que el estado tiene desigualdades no reveladas por estos promedios. La encuesta nos permite concluir que la desigualdad ha ido en aumento a lo largo de los años y que las diferencias en las ganancias salariales entre la Escuela Secundaria y la Educación Superior superan el 150\%. Existe una tendencia a la concentración de trabajadores con Educación Secundaria a expensas de otros niveles educativos.

Palabras clave: Educación Superior. Desigualdad. Ingresos. Enseñanza. Índice de Gini. 


\section{Referências}

ATLAS DO DESENVOLVIMENTO HUMANO NO BRASIL. Como está o desenvolvimento humano no Brasil? Brasília, DF, 2018. Disponível em: http://www.atlasbrasil.org.br/. Acesso em: jul. 2018.

BAPTISTA FILHO, O. Economia da educação, planejamento e explosão demográfica. São Paulo: Pioneira, 1975.

BARBOSA FILHO, F. H.; PESSÔA, S. Educação, crescimento e distribuição de renda: a experiência brasileira em perspectiva histórica. In: Veloso, F., et al. (orgs.). Educação básica no Brasil. São Paulo: Elsevier, 2009. Vol. 1, p. 51-72.

BARROS, R. P.; HENRIQUES, R.; MENDONÇA, R. A estabilidade inaceitável: desigualdade e pobreza no Brasil. Rio de Janeiro: IPEA, 2001. (Texto para discussão, 800)

BRASIL. Ministério da Economia. Programa de Disseminação de Estatística do Trabalho. Relação Anual de Informações Sociais (RAIS). Brasília, DF, 2018.

FERREIRA, F. H. G. Os determinantes da desigualdade de renda no Brasil: luta de classes ou heterogeneidade educacional? Rio de Janeiro: Departamento de Economia PUC-Rio, 2000. (Texto para discussão, 415).

FERREIRA, S. G.; VELOSO, F. A. A escassez de educação. In: GIAMBIAGI, F. Economia brasileira contemporânea. Rio de Janeiro: Elsevier, 2005..

FONSECA, M. A. R. Planejamento e desenvolvimento econômico. São Paulo: Thomson Learning, 2006.

GRAMANI, M. C. Análise dos determinantes de eficiência educacional do estado do Ceará. Ensaio: Avaliação e Políticas Públicas em Educação, Rio de Janeiro, v. 25, n. 95, p. 507-526, abr./jun. 2017. https://doi.org/10.1590/s0104-40362017002500811

HOFFMANN, R. Estatística para economistas. São Paulo: Cengage Learning, 2009.

INSTITUTO NACIONAL DE ESTUDOS E PESQUISAS EDUCACIONAIS ANÍSIO TEIXEIRA - INEP. Censo Escolar de 2017. Brasília, DF, 2017. Disponível em: http://portal.inep.gov.br/web/guest/microdados. Acesso em: jul. 2018. 
JANNUZZI, P. M. Indicadores sociais no Brasil: conceitos, fontes de dados e aplicações. Campinas: Alínea 2006.

LAMEIRAS, M. N. P; VASCONCELOS, L. S. A evolução da população ocupada com nível superior no mercado de trabalho. Carta de Conjuntura, Brasília, DF, n. 41, p. 1-7, $4^{\circ}$ trim. 2018.

LANGONI, C. Distribuição de renda e desenvolvimento econômico do Brasil. Rio de Janeiro: Editoria FGV, 2005.

PEREIRA, G. M. C., et al. Panorama de oportunidades para os egressos do ensino superior no Brasil: o papel da inovação na criação de novos mercados de trabalho. Ensaio: Avaliação e Políticas Públicas em Educação, Rio de Janeiro, v. 24, n. 90, p. 179-198, jan./mar. 2016. https://doi.org/10.1590/S0104-40362016000100008

RAMOS, L.; MENDONÇA, R. Pobreza e desigualdade de renda no Brasil. In: GIAMBIAGI, F. Economia brasileira contemporânea. Rio de Janeiro: Elsevier, 2005.

RAMOS, L.; REIS, M. A escolaridade dos pais e os retornos à educação no mercado de trabalho. Rio de Janeiro: IPEA, 2009. (Texto para discussão, n. 1442).

SOUZA, N. J. Desenvolvimento econômico. São Paulo: Atlas, 2009.

THOMAS, V.; WANG, Y.; FAN, X. Measuring education inequality: Ginni coefficients of education. Washington, DC: The World Bank, 2001. (Policy Research Working Paper, 2525).

TODOS PELA EDUCAÇÃO. Anuário Brasileiro da Educação Básica 2018. [S. n. t.]. Disponível em: http://www.todospelaeducacao.org.br/ biblioteca/1493/anuario-brasileiro-da-educacao-basica-2018/. Acesso em: jul. 2018. 


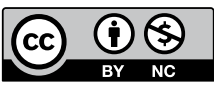

\section{Informações sobre os autores}

Amanda Maciel da Silva: Mestre em Administração pela Universidade do Estado de Santa Catarina. Contato: amandamacieldasilva@gmail.com

(iD) https://orcid.org/0000-0003-1301-9926

Mário César Barreto de Moraes: Doutor em Engenharia de Produção. Professor do Programa de Pós-Graduação em Administração da Universidade do Estado de Santa Catarina. Contato: mcbmstrategos@gmail.com

iD https://orcid.org/0000-0002-0760-8444

Sulivan Desirée Fischer: Doutora em Administração Pública. Diretora de Direitos Humanos na Secretaria de Estado do Desenvolvimento Social de Santa Catarina. Professora do Departamento de Administração Pública do Centro de Ciências da Administração e Socioeconômicas da Universidade do Estado de Santa Catarina. Contato: sulivan.fischer@gmail.com

(iD) https://orcid.org/0000-0002-8273-3931

Claudia Maffini Griboski: Doutora em Educação. Professora do Programa de Pós-Graduação em Educação, Modalidade Profissional, da Universidade de Brasília. Contato: cgriboski4@gmail.com

iD https://orcid.org/0000-0002-5203-7927 